\title{
Parsing struktur semantik soal cerita matematika berbahasa indonesia menggunakan recursive neural network
}

\section{Parsing the semantic structure of indonesian math word problems using the recursive neural network}

\author{
Agung Prasetya a, Chastine Fatichah ${ }^{b}$, Umi Laili Yuhana ${ }^{c}$ \\ $a, b, c$ Teknik Informatika, Institut Teknologi Sepuluh Nopember, Surabaya, Indonesia \\ email:aprasetya.agung@gmail.com, bchastine@if.its.ac.id, cyuhana@if.its.ac.id
}

\begin{tabular}{l}
\hline I N F O A R T I K E L \\
\hline Sejarah artikel: \\
Menerima 15 Januari 2019 \\
Revisi 1 Juni 2019 \\
Diterima 1 Juni 2019 \\
Online 27 Juni 2019 \\
\hline Kata kunci: \\
parsing \\
pohon biner \\
Recursive Neural Network \\
soal cerita \\
struktur semantik \\
\hline
\end{tabular}

\section{Keywords:}

binary tree

math word problem

semantic structure

parsing

Recursive Neural Network

Style APA dalam menyitasi artikel ini:

Prasetya, A., Fatichah, C., \& Yuhana, U. L. (2019). Parsing struktur semantik soal cerita matematika berbahasa indonesia menggunakan recursive neural network. Register: Jurnal Ilmiah Teknologi Sistem Informasi, 5(2), 106-115

\begin{abstract}
ABSTRAK
Soal cerita berperan penting untuk kemajuan pengembangan kecerdasan buatan. Hal ini karena penyelesaian soal cerita melibatkan pengembangan sebuah sistem yang mampu memahami bahasa alami. Pembentukan sistem penyelesaian soal memerlukan mekanisme untuk mendekomposisikan teks soal ke segmen-segmen teks untuk diterjemahkan ke jenis operasi hitung. Segmen-segmen tersebut ditentukan melalui proses parsing semantik struktur soal agar menghasilkan segmen-segmen yang maknanya menunjuk operasi hitung. Sejumlah metode usulan saat ini sesuai untuk diterapkan pada soal cerita berbahasa Inggris dan belum diterapkan pada soal cerita berbahasa Indonesia. Dampaknya adalah segmen-segmen yang dihasilkan belum tentu menghasilkan urutan pengerjaan operasi yang sesuai makna cerita. Penelitian ini mengusulkan penggunaaan Recursive Neural Network (RNN) sebagai parser struktur semantik soal cerita berbahasa Indonesia. Pengujian parser struktur semantik soal dilakukan terhadap soal-soal yang berasal dari Buku Sekolah Elektronik (BSE) Sekolah Dasar (SD) dari Pusat Perbukuan Kementerian Pendidikan dan Kebudayaan. Hasil pengujian menunjukkan akurasi akhir sebesar $86,4 \%$.
\end{abstract}

\section{ABSTRACT}

Math word problems play an important role for the development of artificial intelligent. This is because solving word problems involves the development of a system that can understand natural language. Designing a system for solving math word problems requires a mechanism for decomposing a text into segments of text to be translated into math operation. The segments are categorized through the process of parsing the semantic structure of the word problems to obtain segments whose meanings refer to math operation. A number of current proposed methods are suitable to be applied to English math word problems and have never been applied to Indonesian math word problems. The impact is that the segments produced are not necessarily in line with the sequences of operations appropriate with the meaning of the story. This study proposed the use of Recursive Neural Network (RNN) as a parser of semantic structure of Indonesian math word problems. The testing of the parser was carried out on the math word problems taken from the Elementary School's Electronic School Book (BSE) published by the Book Center of the Ministry of Education and Culture. The result of the testing showed that the final accuracy was $86.4 \%$.

(c) 2019 Register: Jurnal IImiah Teknologi Sistem Informasi. Semua hak cipta dilindungi undang-undang.

\section{Pendahuluan}

Soal cerita berperan penting untuk kemajuan pengembangan kecerdasan buatan (Clark \& Etzioni, 2016; Clark, 2015). Hal ini karena penyelesaian soal cerita melibatkan pengembangan sebuah sistem yang 
mampu memahami bahasa alami. Sistem yang dikembangkan tersebut harus dapat memberikan jawaban ketika diberikan sebuah narasi dan pertanyaan.

Pembentukan sistem penyelesaian soal memerlukan mekanisme untuk mengidentifikasi jenis operasi hitung. Sejumlah penelitian mengidentifikasi keseluruhan jenis operasi dengan menyeleksi kerangka atau template persamaan yang cocok dengan soal (Zhou, Dai, \& Chen, 2015 ; Kushman, Artzi, Zettlemoyer, \& Barzilay, 2014; Upadhyay, Chang, Chang, \& Yih, 2016; Mitra \& Baral, 2016; Wang, Liu, \& Shi, 2017; Wang, et al., 2018). Mekanisme ini mensyaratkan ketersediaan sebuah repositori yang diasumsikan bahwa template pada repositori mencakup berbagai bentuk soal. Mekanisme berbasis template ini kurang efektif ketika dihadapkan pada sebuah soal yang persamaannya tidak tersedia pada repositori. Untuk memperbaiki hal ini, sejumlah penelitian mendekomposisikan teks soal terlebih dahulu ke sejumlah segmen teks (Koncel-Kedziorski, Hajishirzi, Sabharwal, Etzioni, \& Ang, 2015; Roy, Vieira, \& Roth, 2015). Segmen-segmen teks tersebut kemudian diklasifikasikan ke operasi hitung dengan menggunakan model klasifikasi teks. Selain lebih efektif untuk mengidentifikasi jenis operasi pada soal campuran yang kompleks, mekanisme ini lebih efisien karena tidak memerlukan proses pembentukan repositori.

Performa mekanisme identifikasi jenis operasi dengan mendekomposisikan soal sangat dipengaruhi oleh proses penentuan segmen. Penentuan segmen tidak dapat diselesaikan hanya dengan membatasi bagian-bagian tertentu teks menggunakan dua operand. Pemecahan teks soal ke segmen perlu memperhitungkan struktur semantik soal agar menghasilkan segmen-segmen yang maknanya menunjuk ke operasi hitung. Tetapi, metode-metode berbasis dekomposisi teks yang telah diusulkan di atas sesuai untuk diterapkan pada soal cerita berbahasa Inggris dan belum tentu sesuai untuk menyelesaikan soal cerita berbahasa Indonesia. Ketika menghadapi kasus soal campuran, hal ini berpotensi menghasilkan urutan pengerjaan operasi yang tidak sinkron dengan makna cerita.

Berdasarkan permasalahan di atas, sebuah metode sangat diperlukan untuk melakukan parsing struktur semantik soal berbahasa Indonesia. Proses parsing tersebut dimodelkan sebagai permasalahan dalam memprediksi struktur. Makalah ini mengusulkan penerapan Recursive Neural Network (RvNN) untuk menyelesaikan prediksi struktur semantik soal bahasa Indonesia. Model RvNN sebelumnya telah berhasil digunakan untuk menyelesaikan masalah parsing sintaksis kalimat dan parsing struktur image (Socher, Lin, Ng, \& Manning, 2011; Socher, Pennington, Huang, Ng, \& Manning, 2011).

\section{Usulan Metode Parsing Struktur Semantik Soal Cerita Berbahasa Indonesia}

Metode usulan untuk parsing struktur semantik soal cerita tersusun atas tiga proses utama, yaitu merepresentasikan kalimat ke vektor semantik, enumerasi himpunan kandidat pohon biner, dan scoring setiap kandidat pohon biner berbasis RvNN. Proses pertama mengambil masukan berupa teks soal cerita. Proses ini akan memecah soal ke dalam beberapa kalimat. Setiap kalimat akan direpresentasikan ke vektor berdimensi $n$ menggunakan model Recursive Autoencoder. Proses yang kedua berupaya mendapatkan berbagai kemungkinan pohon biner yang dapat dibentuk dengan diberikan sejumlah kalimat. Proses yang terakhir menghitung skor dan memilih skor maksimum dari kandidat-kandidat pohon biner. Blok diagram metode usulan ditunjukkan pada Gambar 1.

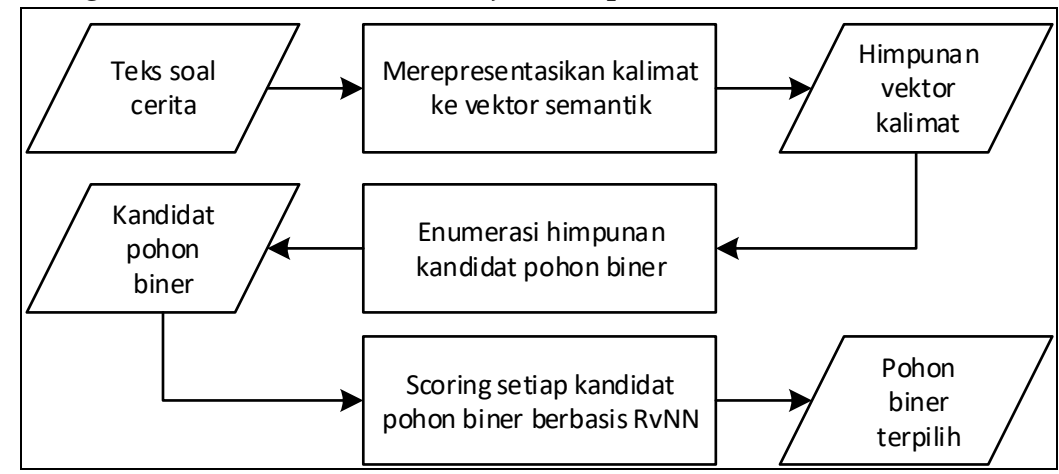

Gambar 1. Blok diagram metode usulan parsing struktur semantik soal cerita

Parsing struktur soal berupaya untuk mendapatkan pohon biner yang merepresentasikan struktur makna soal cerita. Penelitian ini menerapkan model RvNN (Socher, Lin, Ng, \& Manning, 2011; Socher, Huang, Pennington, Ng, \& Manning, 2011; Socher, Pennington, Huang, Ng, \& Manning, 2011) Parsing struktur semantik soal cerita matematika berbahasa indonesia menggunakan ... http://doi.org/10.26594/register.v5i2.1537 (c) 2019 Register: Jurnal IImiah Teknologi Sistem Informasi. Semua hak cipta dilindungi undang-undang 
untuk menghitung skor dari berbagai kemungkinan bentuk pohon biner dari sebuah soal. RvNN diintegrasikan pada sebuah fungsi prediksi $f$. Fungsi prediksi $f$ akan memilih sebuah pohon biner yang maksimum. Dengan demikian, fungsi prediksi $f$ harus dibentuk agar menghasilkan skor yang tinggi untuk pohon biner yang benar dan memberikan skor yang rendah untuk pohon biner-pohon biner yang salah. Diberikan sebuah teks soal $x$ yang tersusun atas $n$-kalimat dan parameter $\operatorname{RvNN} \theta$, fungsi prediksi $f$ dapat didefinisikan pada Persamaan 1 ,

$f(x, \theta)=\arg \max _{t \in T(x)} R v N N(t, \theta)$

yang mana $T(x)$ merupakan himpunan pohon biner yang dapat dibentuk dari soal $x$.

RvNN pada prinsipnya merupakan sebuah arsitektur Neural Network yang terdiri dari dua buah layer yang masing-masing menggunakan fungsi aktivasi nonlinear dan linear. Dua buah layer ini melekat pada setiap node nonterminal pada pohon biner. RvNN hanya dapat bekerja jika struktur pohon biner telah terbentuk. Gambar 2 menunjukkan contoh penggunaan RvNN untuk menghitung skor sebuah pohon biner dari soal "Budi memiliki 5 mangga. Ia memberikan pada Ani 2 mangga. Berapa sisa mangga Budi?".

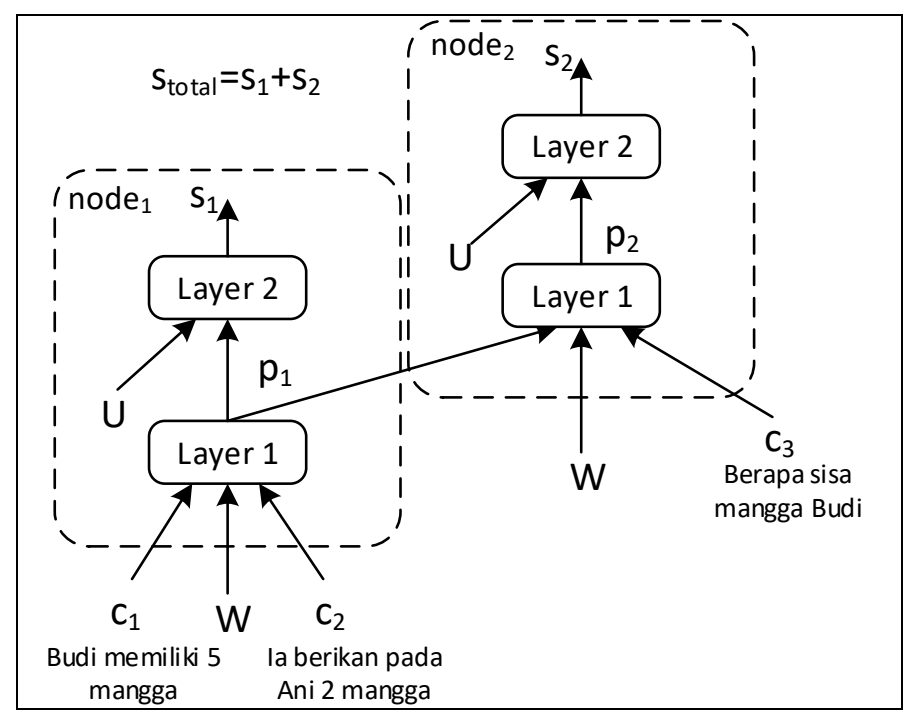

Gambar 2. Contoh penerapan RvNN untuk menghitung skor sebuah pohon biner dari soal

Seperti yang ditunjukkan pada contoh di atas, skor total s_total sebuah pohon biner diperoleh dengan menjumlahkan skor pada keseluruhan node. Skor node s merupakan output dari fungsi linear pada layer 2. Fungsi linear pada layer 2 mengambil dua jenis masukan, yaitu parameter $U$ dan vektor $p$. Vektor $p$ yang berdimensi $n$ merupakan output fungsi nonlinear pada layer 1 . Fungsi nonlinear pada layer 1 mengambil tiga masukan salah satunya adalah parameter $W$. Dua masukan lain adalah dua vektor kalimat jika layer 1 berada pada node leaf. Jika layer 1 berada pada node nonleaf maka masukan dapat berupa vektor output layer 1 yang berasal dari node child. Pada RvNN, setiap node berbagi parameter layer 1 dan layer 2 yang sama. Proses perhitungan skor total dilakukan secara buttom-up dimulai dari node leaf hingga ke root.

Perhitungan skor total hanya dapat dilakukan jika kalimat-kalimat soal telah direpresentasikan sebagai vektor berdimensi $n$. Untuk mengubah kalimat ke vektor, penelitian ini menggunakan Recursive Autoencoder (Socher, et al., 2013). Vektor dari hasil proses penerapan Recursive Autoencoder merepresentasikan semantik kalimat. Mekanisme ini memanfaatkan vektor kata dan struktur sintaks kalimat untuk mendapatkan sebuah vektor yang merepresentasikan makna kalimat. Untuk merepresentasikan kata ke vektor, penelitian ini menggunakan model Skip-Gram (Mikolov, Chen, Corrado, \& Dean, 2013; Mikolov, Sutskever, Chen, Corrado, \& Dean, 2013). Sedangkan struktur sintaks kalimat diperoleh dengan menggunakan algoritma Shift-Reduce-Parser (Zhu, Zhang, Chen, Zhang, \& $\mathrm{Zhu}, 2013$ ).

Fungsi prediksi pada Persamaan 1 memerlukan mekanisme untuk mendapatkan himpunan pohon biner dari sebuah soal. Pada penelitian ini, himpunan tersebut diperoleh dengan cara mengenumerasi semua kemungkinan bentuk pohon biner yang dapat dibentuk dari sebuah soal. 
Walaupun cara ini kurang efisien, jenis soal yang digunakan pada penelitian ini relatif sederhana, tersusun atas $2-4$ kalimat sehingga tidak mengalami kendala. Penelitian selanjutnya dapat mempertimbangkan mekanisme lain yang lebih efisien untuk pembentukan himpunan pohon biner.

Parameter $\theta$ pada Persamaan 1 merujuk pada parameter layer 1 dan layer $2, U$ dan $W$. Parameter ini perlu dioptimalkan agar menghasilkan skor total yang tinggi pada pohon biner yang benar dan skor total yang rendah untuk pohon biner yang salah. Optimasi parameter $\theta$ dilakukan dengan supervised learning. Proses learning berupaya menentukan parameter $\theta$ dengan menggunakan sejumlah dataset yang terdiri dari $m$-pasangan soal $x$ dan pohon biner soal $t,\left\{\left(x_{i}, t_{i}\right)\right\}_{i=1}^{m}$. Fungsi objektif untuk proses learning ditunjukkan pada Persamaan 2 (Socher, Lin, Ng, \& Manning, 2011; Ratlif, Bagnell, \& Zinkevich, 2006),

$J(\theta)=\frac{\lambda}{2}\|\theta\|^{2}+\frac{1}{m} \sum_{i=1}^{m} \max _{t \in T\left(x_{i}\right)}\left\{l\left(t_{i}, t\right)+R v N N(t, \theta)\right\}-R v N N\left(t_{i}, \theta\right)$

yang mana $\lambda$ merupakan bobot regularizer dan $l$ merupakan fungsi structured loss margin yang mengukur perbedaan struktur dua buah pohon biner. Proses learning akan mengubah nilai $\theta$ agar RvNN dapat menghasilkan skor yang lebih tinggi untuk pohon biner yang benar (pohon biner yang disediakan pada dataset) $t_{i}$ dibandingkan dengan skor pohon biner yang salah $t \in T\left(x_{i}\right) \backslash t_{i}$. Perbedaan nilai skor kedua pohon biner tersebut mengikuti nilai fungsi $l$.

Mengikuti Taskar, Klein, Collins, Koller, dan Manning (2004), fungsi $l$ ditentukan berdasarkan jumlah perbedaan index span antara dua pohon. Span merupakan pasangan index yang menunjukkan posisi kalimat paling kiri dan kanan yang ada di bawah sebuah node nonleaf. Fungsi $l$ menjumlahkan total index span yang berbeda di semua nonterminal node. Index span yang berbeda bernilai 1, jika sama maka bernilai 0. Gambar 2 mengilustrasikan pemberian index span di setiap node pada sebuah pohon biner.

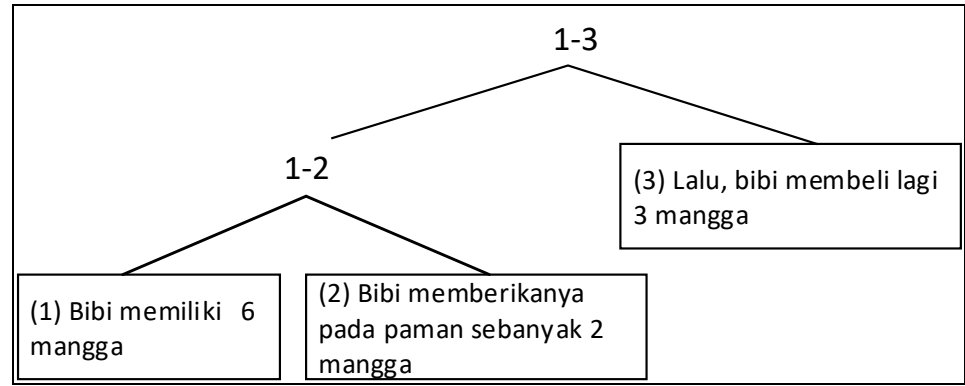

Gambar 3. Index span pada sebuah pohon biner untuk soal

\section{Hasil Uji Coba dan Pembahasan}

\subsection{Dataset}

Penelitian ini menggunakan soal-soal cerita di Buku Sekolah Elektronik (BSE) yang disediakan oleh Pusat Perbukuan Kementerian Pendidikan dan Kebudayaan. BSE tersebut diunduh dari website http://bse.kemdikbud.go.id/. Penelitian ini menggunakan soal-soal yang mengandung maksimal dua operasi hitung dasar (penjumlahan, pengurangan, perkalian, dan pembagian). Selain itu, penelitian ini mengabaikan soal-soal yang memerlukan proses konversi satuan dan mengabaikan soal-soal yang memerlukan informasi tambahan untuk menyelesaikanya. Tabel 1 menunjukkan jumlah soal cerita yang telah dikumpulkan dari beberapa BSE kelas 1-4 sekolah dasar.

Tabel 1. Informasi detail mengenai dataset

\begin{tabular}{lc}
\hline \multicolumn{1}{c}{ Jenis Karakteristik Dataset } & Nilai \\
\hline Jumlah total soal & 1212 \\
Jumlah soal campuran & 308 \\
Jumlah soal noncampuran & 904 \\
Jumlah soal dengan jumlah kalimat $<3$ & 167 \\
\hline
\end{tabular}

Setiap soal selanjutnya disusun ke struktur pohon biner. Setiap node nonterminal memiliki tepat 2 cabang. Setiap node baik terminal maupun leaf memiliki salah satu label dari 5 jenis label. Label-label ini merepresentasikan jenis operasi hitung dasar yang antara lain penjumlahan, pengurangan, 
perkalian, pembagian, dan nonoperator. Proses pembentukan struktur pohon biner soal dibantu dengan sebuah aplikasi untuk pembentukan Rhetorical Structure, yaitu RST Tool versi 3.0 (O'Donnell, 2000).

Ada beberapa pemrosesan teks kalimat sebelum proses pembentukan struktur pohon biner, antara lain: 1) mengganti setiap token angka, 2) tanggal atau waktu menjadi token khusus yaitu num, date atau time, 3) mengubah setiap huruf kapital ke huruf kecil, dan 4) menghapus setiap tanda baca kecuali tanda penghubung "-" untuk kata jamak.

Soal-soal yang menjadi data latih parser struktur semantik memiliki lebih dari 2 kalimat. Soalsoal yang hanya tersusun atas 1 atau 2 kalimat menyebabkan bias dalam proses training, karena hanya ada satu kemungkinan struktur yang dapat dibentuk. Informasi mengenai jumlah dataset tersaji pada Tabel 1.

Hasil pengumpulan dataset menunjukkan ada 7 jenis pola pohon biner yang dapat dikumpulkan. Pola-pola ini sudah meliputi soal cerita yang tersusun atas dua kalimat. Pola-pola ini dapat dianggap sebagai kelas-kelas RvNN. Jumlah soal untuk masing-masing pola ditunjukkan pada Tabel 2. Sedangkan contoh soal cerita yang tergolong pola 1 dan pola 3 ditunjukkan pada Gambar 4 dan Gambar 5 .

Tabel 2. Jenis dan jumlah soal

\begin{tabular}{cc}
\hline Jenis Pola & Jumlah Pola \\
\hline Jumlah Pola 1 & 142 \\
Jumlah Pola 2 & 166 \\
Jumlah Pola 3 & 161 \\
Jumlah Pola 4 & 124 \\
Jumlah Pola 5 & 145 \\
Jumlah Pola 6 & 230 \\
Jumlah Pola 7 & 244 \\
\hline
\end{tabular}

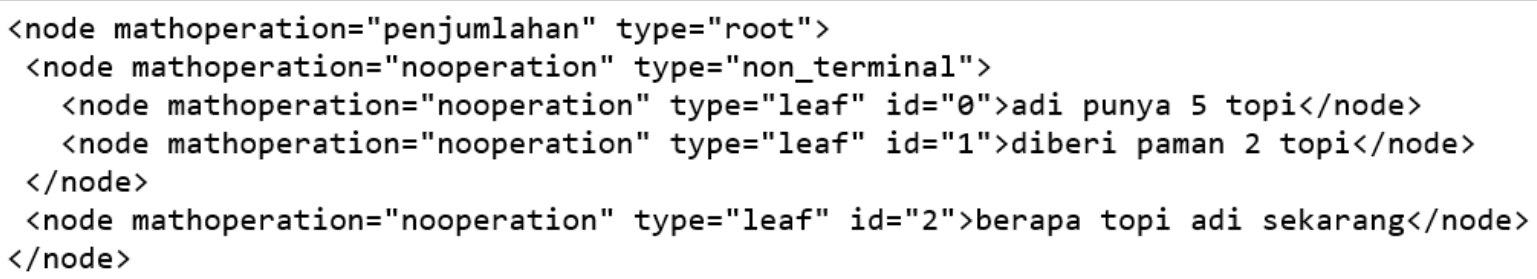

Gambar 4. Contoh soal cerita yang tergolong pola 1

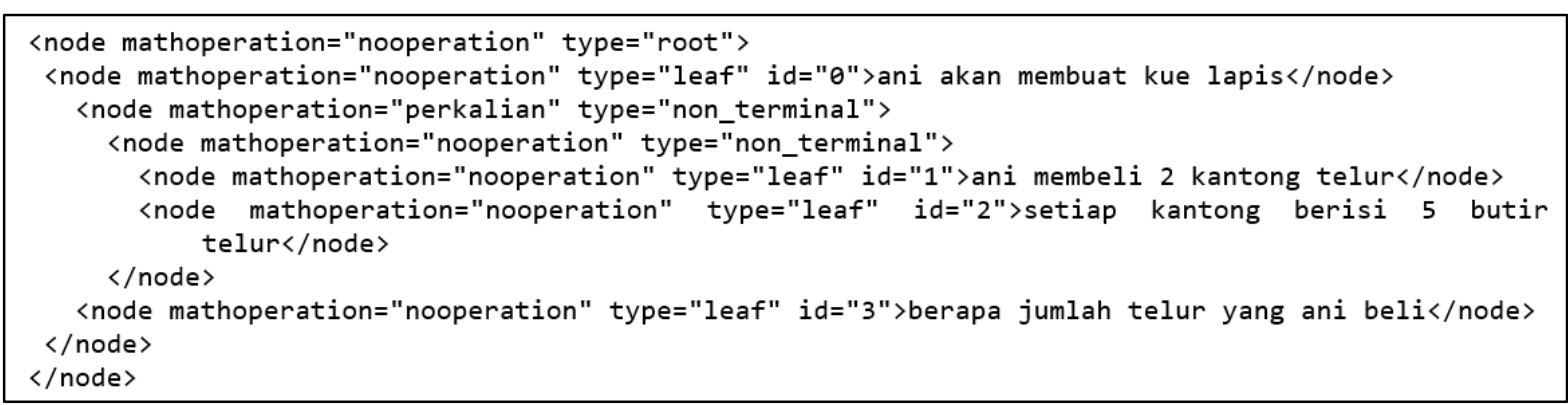

Gambar 5. Contoh soal cerita yang tergolong pola 3

\subsection{Hasil Uji Coba Parsing Struktur Soal Cerita Berbahasa Indonesia}

Penentuan parameter Recursive Neural Network $(W, b, U)$ untuk parser dilakukan melalui supervised learning. Sebelum melakukan pelatihan, pada penelitian ini, setiap kalimat direpresentasikan ke sebuah vektor menggunakan model Recursive Autoencoder (Socher, et al., 2013). Recursive Autoencoder memerlukan mekanisme untuk mengubah kata ke vektor. Penelitian ini menggunakan model SkipGram untuk mengubah kata ke vektor. Pengujian yang dilakukan mempertimbangkan dimensi vektor kata sebesar 50, 100, dan 200. 
Penelitian ini menerapkan $k$-fold cross validation dengan $k=5$ untuk mengurangi bias dalam mengevaluasi penentuan parameter RvNN. Data yang digunakan untuk data pelatihan maupun pengujian ditentukan dengan membagi terlebih dahulu soal-soal pada setiap pola sebanyak jumlah fold. Pembagian ini dilakukan secara acak. Setelah soal-soal per pola terkelompokkan, selanjutnya untuk setiap fold, kelompok-kelompok per pola tersebut digabungkan. Beberapa parameter learning perlu dioptimalkan pada proses pelatihan parser antara lain bobot regularizer $\lambda$ dan nilai penalti kuntuk fungsi structure loss Persamaan 1 pada Persamaan 3. Ukuran optimal suatu nilai parameter didasarkan pada tingkat akurasi parser. Pohon biner yang diprediksi oleh parser RvNN bernilai benar jika strukturnya secara tepat sama dengan hasil struktur pohon biner yang disediakan oleh dataset.

Nilai-nilai dari hyperparameter ini dioptimalkan melalui batch subgradient descent. Pengaturan nilai learning rate di setiap iterasi dilakukan dengan menerapkan rule Constant Step Length. Rule Constant Step Length menentukan nilai learning rate untuk setiap iterasi $i$ dengan $\alpha_{i}=\gamma /\left\|g_{i}\right\|_{2}$, di mana $g_{i}$ merupakan gradient parameter untuk iterasi ke-i dan $\gamma$ merupakan sebuah koefisien dengan $\gamma>0$. Pada penelitian ini, nilai koefisien $\gamma$ ditetapkan sebesar 0,8 . Berdasarkan eksperimen awal yang telah dilakukan, rule ini memiliki tingkat convergence yang lebih cepat dibandingkan rule lain untuk kasus ini. Tabel 3 menunjukkan beberapa parameter yang akan dioptimalkan pada proses pelatihan.

Tabel 3. Parameter RvNN yang diuji coba

\begin{tabular}{ll}
\hline \multicolumn{1}{c}{ Nama Parameter } & \multicolumn{1}{c}{ Nilai-nilai yang diuji coba } \\
\hline Nilai bobot L2-regularizer $(\lambda)$ & $1 \mathrm{e}-6,1 \mathrm{e}-5,1 \mathrm{e}-4,5 \mathrm{e}-4,1 \mathrm{e}-3,5 \mathrm{e}-3,1 \mathrm{e}-2$ \\
Nilai penalti structure loss $(\kappa)$ & 1,$0 ; 0,9 ; 0,8 ; 0,7 ; 0,6$ \\
Dimensi vektor kata & 50,100 dan 200 \\
\hline
\end{tabular}

Subgradient descent belum tentu menghasilkan nilai fungsi objektif yang menurun untuk iterasi berikutnya. Hal ini karena penggunaan operasi max pada fungsi objektif. Pada setiap iterasi, parameter RvNN yang terbaik akan disimpan sebagai parameter global yang optimal jika fungsi objektif yang dihasilkan pada suatu iterasi lebih optimal daripada iterasi-iterasi sebelumnya.

Uji coba pertama adalah untuk mengetahui pengaruh nilai bobot regularizer $\lambda$ terhadap rata-rata akurasi. Pada skenario ini nilai penalti structure loss $\mathcal{\kappa}$ dan dimensi vektor kata ditetapkan sebesar 0,8 dan 50. Hasil uji coba untuk skenario pertama ditunjukkan pada Tabel 4.

Tabel 4. Hasil akurasi untuk beberapa nilai L2-regularizer dengan nilai penalti sebesar 0,8 dan vektor kata 50

\begin{tabular}{ccccccc}
\hline \multirow{2}{*}{ Bobot L2-regularizer ( $\boldsymbol{\lambda}$ ) } & $\begin{array}{c}\text { Akurasi } \\
\text { fold 0 }\end{array}$ & $\begin{array}{c}\text { Akurasi } \\
\text { fold 1 }\end{array}$ & $\begin{array}{c}\text { Akurasi } \\
\text { fold 2 }\end{array}$ & $\begin{array}{c}\text { Akurasi } \\
\text { fold 3 }\end{array}$ & $\begin{array}{c}\text { Akurasi } \\
\text { fold 4 }\end{array}$ & Rata-rata Akurasi \\
\hline 1e-6 & 0,893 & 0,889 & 0,857 & 0,833 & 0,764 & 0,847 \\
1e-5 & 0,887 & 0,878 & 0,857 & 0,839 & 0,779 & 0,848 \\
1e-4 & $\mathbf{0 , 8 8 1}$ & $\mathbf{0 , 8 9 6}$ & $\mathbf{0 , 8 5 7}$ & $\mathbf{0 , 8 4 2}$ & $\mathbf{0 , 8 0 7}$ & $\mathbf{0 , 8 5 6}$ \\
5e-4 & 0,884 & 0,898 & 0,851 & 0,836 & 0,793 & 0,852 \\
1e-3 & 0,875 & 0,893 & 0,863 & 0,845 & 0,787 & 0,852 \\
5e-3 & 0,893 & 0,890 & 0,859 & 0,835 & 0,764 & 0,848 \\
1e-2 & 0,890 & 0,890 & 0,854 & 0,857 & 0,776 & 0,853 \\
\hline
\end{tabular}

Tabel 5. Hasil akurasi untuk beberapa nilai penalti structure loss dengan bobot L2 sebesar 1e-4 dan vektor kata 50

\begin{tabular}{ccccccc}
\hline Nilai Penalti Structure loss $(\kappa)$ & $\begin{array}{c}\text { Akurasi } \\
\text { fold 0 }\end{array}$ & $\begin{array}{c}\text { Akurasi } \\
\text { fold 1 }\end{array}$ & $\begin{array}{c}\text { Akurasi } \\
\text { fold 2 }\end{array}$ & $\begin{array}{c}\text { Akurasi } \\
\text { fold 3 }\end{array}$ & $\begin{array}{c}\text { Akurasi } \\
\text { fold 4 }\end{array}$ & Rata-rata Akurasi \\
\hline 0.9 & 0.893 & 0.893 & 0.857 & 0.833 & 0.784 & 0.852 \\
$\mathbf{0 . 8}$ & $\mathbf{0 . 8 8 1}$ & $\mathbf{0 . 8 9 6}$ & $\mathbf{0 . 8 5 7}$ & $\mathbf{0 . 8 4 2}$ & $\mathbf{0 . 8 0 7}$ & $\mathbf{0 . 8 5 6}$ \\
0.7 & 0.901 & 0.890 & 0.848 & 0.836 & 0.784 & 0.852 \\
0.6 & 0.878 & 0.886 & 0.859 & 0.848 & 0.801 & 0.854 \\
\hline
\end{tabular}

Tabel 4 menunjukkan hasil rata-rata akurasi terbaik diberikan ketika nilai bobot L2-regularizer sebesar 1e-4, yaitu 0,856. Meskipun demikian, perbedaan antara ketujuh nilai tidak terlalu tajam. Perubahan nilai bobot L2 tidak terlalu memengaruhi nilai rata-rata akurasi. Uji coba berikutnya bertujuan mengetahui pengaruh nilai penalti structure loss $\kappa$. Pada uji coba ini, nilai bobot L2-regularizer 
ditetapkan berdasarkan hasil terbaik pada uji coba sebelumnya, yaitu sebesar 1e-4. Sedangkan vektor kata ditetapkan sebesar 50. Hasil rata-rata akurasi pada uji coba ini ditunjukkan pada Tabel 4.

Tabel 5 menunjukkan hasil akurasi terbaik yaitu 0,856 diberikan oleh nilai penalti structure loss sebesar 0,8 . Sama halnya dengan uji coba sebelumnya, perubahan nilai rata-rata akurasi tidak terlalu tajam terhadap perubahan nilai penalti structure loss. Variasi nilai penalti tidak terlalu memengaruhi hasil rata-rata akurasi parser berbasis RvNN. Uji coba ketiga bertujuan untuk mengetahui pengaruh vektor kata terhadap rata-rata akurasi parsing. Pada skenario ini, bobot L2 dan nilai penalti structure loss ditetapkan berdasarkan nilai uji coba sebelumnya, yaitu sebesar 1e-4 dan 0.8 . Hasil uji coba pada skenario ketiga ditunjukkan pada Tabel 6 .

Tabel 6. Hasil akurasi dari beberapa ukuran dimensi vektor kata

\begin{tabular}{ccccccc}
\hline $\begin{array}{c}\text { Dimensi vektor } \\
\text { kata }\end{array}$ & fold 0 & fold 1 & fold 2 & fold 3 & fold 4 & $\begin{array}{c}\text { Rata-Rata } \\
\text { akurasi }\end{array}$ \\
\hline 50 & 0,881 & 0,896 & 0,857 & 0,842 & 0,807 & 0,856 \\
100 & 0,887 & 0,898 & 0,901 & 0,811 & 0,790 & 0,857 \\
$\mathbf{2 0 0}$ & $\mathbf{0 , 8 7 8}$ & $\mathbf{0 , 8 9 0}$ & $\mathbf{0 , 8 6 9}$ & $\mathbf{0 , 8 3 9}$ & $\mathbf{0 , 8 4 5}$ & $\mathbf{0 , 8 6 4}$ \\
\hline
\end{tabular}

Tabel 6 menunjukkan hasil rata-rata akurasi terbaik diberikan oleh dimensi vektor kata sebesar 200. Tabel 6 juga menunjukkan bahwa hasil rata-rata akurasi semakin meningkat ketika dimensi vektor kata semakin besar. Meskipun demikian, peningkatan rata-rata akurasi tidak terlalu tajam.

\subsection{Pembahasan Hasil Uji Coba}

Tabel 7. Contoh hasil parsing struktur semantik soal yang benar

\begin{tabular}{|c|c|c|}
\hline Soal cerita & Prediksi & Aktual \\
\hline $\begin{array}{l}\text { Avi mendapat } 50 \text { butir } \\
\text { telur asin. Diberikan } \\
\text { kepada tetangganya } 30 \\
\text { butir. Ibu membeli lagi } \\
20 \text { butir telur asin. } \\
\text { Berapa butir telur asin } \\
\text { yang ada di rumah Avi } \\
\text { sekarang? }\end{array}$ & $\begin{array}{l}\text { [0-3] null } \\
\text { [0-2] null } \\
\text { [0-1] null } \\
\text { [0] avi mendapat } 50 \text { butir telur asin } \\
\text { [1] diberikan kepada tetangganya } 30 \text { butir } \\
\text { [2] ibu membeli lagi } 20 \text { butir telur asin } \\
\text { [3] berapa butir telur asin yang ada di } \\
\text { rumah avi sekarang }\end{array}$ & $\begin{array}{l}\text { [0-3] null } \\
\text { [0-2] null } \\
\text { [0-1] null } \\
\text { [0] avi mendapat } 50 \text { butir telur asin } \\
\text { [1] diberikan kepada tetangganya } 30 \text { butir } \\
\text { [2] ibu membeli lagi } 20 \text { butir telur asin } \\
\text { [3] berapa butir telur asin yang ada di rumah } \\
\text { avi sekarang }\end{array}$ \\
\hline $\begin{array}{l}\text { Doni mempunyai } 16 \\
\text { buah kacang. Doni } \\
\text { membagi kacang itu } \\
\text { pada kedelapan } \\
\text { temannya. Mereka } \\
\text { mendapatkan kacang } \\
\text { sama banyak. Berapa } \\
\text { kacang yang diterima } \\
\text { masing-masing teman } \\
\text { Doni? }\end{array}$ & $\begin{array}{l}\text { [0-3] null } \\
\text { [0-2] null } \\
\text { [0] doni mempunyai } 16 \text { buah kacang } \\
\text { [1-2] null } \\
\text { [1] doni membagi kacang itu pada } \\
\text { kedelapan temannya } \\
\text { [2] mereka mendapatkan kacang sama } \\
\text { banyak } \\
\text { [3] berapa kacang yang diterima masing- } \\
\text { masing teman doni }\end{array}$ & $\begin{array}{l}\text { [0-3] null } \\
\text { [0-2] null } \\
\text { [0] doni mempunyai } 16 \text { buah kacang } \\
\text { [1-2] null } \\
\text { [1] doni membagi kacang itu pada } \\
\text { kedelapan temannya } \\
\text { [2] mereka mendapatkan kacang sama } \\
\text { banyak } \\
\text { [3] berapa kacang yang diterima masing- } \\
\text { masing teman doni }\end{array}$ \\
\hline $\begin{array}{l}\text { Eni mempunyai } 50 \\
\text { kancing. Kancing- } \\
\text { kancing itu dimasukkan } \\
\text { sama banyak dalam } 5 \\
\text { kotak. Berapakah isi } \\
\text { masing-masing kotak? }\end{array}$ & $\begin{array}{l}{[0-2] \text { null }} \\
{[0-1] \text { null }} \\
\text { [0] eni mempunyai } 50 \text { kancing } \\
\text { [1] kancing-kancing itu dimasukkan sama } \\
\text { banyak dalam } 5 \text { kotak } \\
\text { [2] berapakah isi masing-masing kotak }\end{array}$ & $\begin{array}{l}{[0-2] \text { null }} \\
{[0-1] \text { null }} \\
{[0] \text { eni mempunyai } 50 \text { kancing }} \\
{[1] \text { kancing-kancing itu dimasukkan sama }} \\
\text { banyak dalam } 5 \text { kotak } \\
\text { [2] berapakah isi masing-masing kotak }\end{array}$ \\
\hline
\end{tabular}

Berdasarkan hasil uji coba pertama, perubahan bobot L2-regularizer tidak terlalu memengaruhi hasil rata-rata akurasi parser berbasis RvNN. Perubahan naik maupun turun dari bobot L2 tidak menghasilkan perubahan linear dari rata-rata akurasi. Perbedaan yang tidak terlalu besar ini kemungkinan karena penggunaan fungsi linear pada layer 2 RvNN. Fungsi linear ini menghasilkan bilangan riil dengan batas atas bawah berupa nilai positif atau negatif tak hingga. Karena output dari fungsi linear ini menjadi masukan untuk fungsi objektif, maka fungsi objektif juga akan menghasilkan bilangan riil dengan batas atas atau bawah berupa bilangan tak hingga. Di sisi lain, proses pelatihan mengupayakan nilai parameter di setiap layer $\operatorname{RvNN}$ (parameter $U$ dan $W$ ) agar selalu menghasilkan 
nilai fungsi objektif yang selalu menurun. Proses pelatihan akan menurunkan nilai fungsi objektif tersebut hingga nilai negatif tak hingga. Pada kondisi ini, bobot L2 hanya berfungsi untuk menentukan pergeseran posisi kurva fungsi objektif. Di mana pun posisi kurva fungsi objektif ini, proses pelatihan pada akhirnya akan selalu berupaya menentukan parameter RvNN agar fungsi objektif selalu menuju negatif tak hingga.

Hasil uji coba kedua menunjukkan bahwa perubahan nilai penalti structure loss tidak terlalu mempengaruhi hasil rata-rata akurasi. Hal ini karena fungsinya hanya sebagai skala bagi fungsi structure loss. Akan tetapi, nilai penalti berpengaruh terhadap waktu yang diperlukan untuk convergence ketika learning. Hasil catatan waktu yang diperlukan untuk convergence ketika learning untuk keempat nilai penalti structure loss, yaitu nilai penalti 0,6 sebesar 2,1 jam, nilai penalti 0,7 sebesar 2,21 jam, nilai penalti 0,8 sebesar 2,23 jam, dan nilai penalti 0,9 sebesar 2,58 jam. Hal ini kemungkinan besar disebabkan karena peran dari fungsi structure loss. Nilai dari fungsi structure loss bertindak sebagai margin minimal untuk membedakan antara struktur pohon biner yang benar (pohon biner yang disediakan pada dataset) dengan struktur pohon biner yang salah. Ketika nilai penalti semakin besar maka nilai structure loss semakin besar dan secara otomatis margin juga semakin besar. Untuk mencapai nilai margin yang semakin besar, proses training lebih lama karena memerlukan proses perulangan tambahan untuk mengupdate parameter RvNN.

Hasil uji coba ketiga menunjukkan bahwa ukuran vektor kata memengaruhi hasil rata-rata akurasi parser. Semakin tinggi ukuran dimensi vektor kata, tingkat rata-rata akurasi semakin meningkat. Ukuran dimensi vektor kata ini secara otomatis menjadi ukuran dimensi vektor kalimat maupun vektor gabungan kalimat. Peningkatan rata-rata akurasi kemungkinan karena vektor berdimensi besar memiliki tingkat detail yang lebih tinggi daripada vektor berdimensi rendah pada medan vektor. Beberapa contoh hasil parsing struktur semantik soal yang benar ditunjukkan pada Tabel 7. Sedangkan beberapa contoh hasil parsing struktur semantik soal yang salah ditunjukkan pada Tabel 8.

Tabel 8. Contoh hasil parsing struktur semantik soal yang salah

\begin{tabular}{|c|c|c|}
\hline Soal cerita & Prediksi & Aktual \\
\hline $\begin{array}{l}\text { Pak Umar beternak ayam } \\
\text { ras } 90 \text { ekor. Ayam } \\
\text { tersebut ditempatkan } \\
\text { dalam } 10 \text { buah kandang. } \\
\text { Masing-masing kandang } \\
\text { ditempati ayam dengan } \\
\text { jumlah yang sama. } \\
\text { Berapakah ayam yang } \\
\text { ada dalam tiap kandang? }\end{array}$ & $\begin{array}{l}\text { [0-3] null } \\
\text { [0] pak umar beternak ayam ras } 90 \text { ekor } \\
\text { [1-3] null } \\
\text { [1-2] null } \\
\text { [1] ayam tersebut ditempatkan dalam } 10 \\
\text { buah kandang } \\
\text { [2] masing-masing kandang ditempati } \\
\text { ayam dengan jumlah yang sama } \\
\text { [3] berapakah ayam yang ada dalam tiap } \\
\text { kandang }\end{array}$ & $\begin{array}{l}\text { [0-3] null } \\
\text { [0-2] null } \\
\text { [0] pak umar beternak ayam ras } 90 \text { ekor } \\
\text { [1-2] null } \\
\text { [1] ayam tersebut ditempatkan dalam } 10 \\
\text { buah kandang } \\
\text { [2] masing-masing kandang ditempati } \\
\text { ayam dengan jumlah yang sama } \\
\text { [3] berapakah ayam yang ada dalam tiap } \\
\text { kandang }\end{array}$ \\
\hline $\begin{array}{l}\text { Dengan motor Andi } \\
\text { telah menempuh jarak } 50 \\
\mathrm{~km} \text {. Tiap jam Andi } \\
\text { menempuh jarak } 5 \mathrm{~km} . \\
\text { Berapa jam Andi sudah } \\
\text { mengendarai motor } \\
\text { tersebut? }\end{array}$ & $\begin{array}{l}\text { [0-2] null } \\
{[0-1] \text { null }} \\
\text { [0] dengan motor andi telah menempuh } \\
\text { jarak } 50 \mathrm{~km} \\
\text { [1] tiap jam andi menempuh jarak } 5 \mathrm{~km} \\
\text { [2] berapa jam andi sudah mengendarai } \\
\text { motor tersebut }\end{array}$ & $\begin{array}{l}\text { [0-2] null } \\
\text { [0] dengan motor andi telah menempuh jarak } \\
50 \mathrm{~km} \\
\text { [1-2] null } \\
\text { [1] tiap jam andi menempuh jarak } 5 \mathrm{~km} \\
\text { [2] berapa jam andi sudah mengendarai } \\
\text { motor tersebut }\end{array}$ \\
\hline
\end{tabular}

\section{Kesimpulan}

Kesimpulan yang dapat ditarik dari hasil uji coba adalah model RvNN dapat digunakan sebagai parser struktur semantik soal berbahasa Indonesia. Hasil uji coba menunjukkan tingkat akurasi terbaik sebesar 0,864 atau $86,4 \%$ dengan nilai penalti structure loss sebesar 0,8 ; bobot 12-regularizer sebesar 1e-4 dan ukuran dimensi vektor kata sebesar 200. Hasil uji coba menunjukkan bahwa dimensi vektor kata merupakan faktor yang berpengaruh terhadap hasil rata-rata akurasi parser struktur semantik soal Bahasa Indonesia berbasis RvNN. Ada beberapa hal yang dapat dipertimbangkan untuk penelitian selanjutnya. Hal pertama terkait dengan mekanisme alternatif untuk mengenumerasi kandidat struktur semantik soal sebelum proses scoring. Hal lain yaitu perlunya mempertimbangkan penggabungan 
fungsi objektif untuk parser dan untuk classifier operasi hitung melalui skema joint learning. Penggabungan ini berpotensi menghasilkan parameter RvNN yang sesuai dengan persoalan karena dilatih menggunakan dua fungsi objektif yang berbeda secara bersamaan.

\section{Referensi}

Clark, P. (2015). Elementary School Science and Math Tests as a Driver for AI: Take the Aristo Challenge! Proceedings of the Twenty-Seventh Conference on Innovative Applications of Artificial Intelligence (pp. 40194021). Austin, Texas, USA: AAAI Press.

Clark, P., \& Etzioni, O. (2016). My Computer Is an Honor Student - but How Intelligent Is It? Standardized Tests as a Measure of AI. AI Magazine, 37(1), 5-12.

Koncel-Kedziorski, R., Hajishirzi, H., Sabharwal, A., Etzioni, O., \& Ang, S. D. (2015). Parsing Algebraic Word Problems into Equations. Transactions of the Association for Computational Linguistics, 3, 585-597.

Kushman, N., Artzi, Y., Zettlemoyer, L., \& Barzilay, R. (2014). Learning to Automatically Solve Algebra Word Problems. Proceedings of the 52nd Annual Meeting of the Association for Computational Linguistics (pp. 271-281). Baltimore, Maryland, USA: Association for Computational Linguistics.

Mikolov, T., Chen, K., Corrado, G., \& Dean, J. (2013, January 16). Efficient Estimation of Word Representations in Vector Space. Retrieved from Arxiv: https://arxiv.org/pdf/1301.3781.pdf

Mikolov, T., Sutskever, I., Chen, K., Corrado, G. S., \& Dean, J. (2013). Distributed Representations of Words and Phrases and their Compositionality. Advances in Neural Information Processing Systems 26 (NIPS 2013). Lake Tahoe, Nevada, USA: Neural Information Processing Systems (NIPS).

Mitra, A., \& Baral, C. (2016). Learning To Use Formulas To Solve Simple Arithmetic Problems. Proceedings of the 54th Annual Meeting of the Association for Computational Linguistics (pp. 2144-2153). Berlin, Germany: Association for Computational Linguistics.

O'Donnell, M. (2000). RSTTool 2.4 - A Markup Tool for Rhetorical Structure Theory. INLG'2000 Proceedings of the First International Conference on Natural Language Generation, (pp. 253-256).

Ratlif, N. D., Bagnell, J. A., \& Zinkevich, M. A. (2006). Maximum Margin Planning. International Conference on Machine Learning. Pittsburgh, USA: International Machine Learning Society - ICML.

Roy, S., Vieira, T., \& Roth, D. (2015). Reasoning about Quantities in Natural Language. Transactions of the Association for Computational Linguistics, 3, 1-13.

Socher, R., Huang, E. H., Pennington, J., Ng, A. Y., \& Manning, C. D. (2011). Dynamic Pooling and Unfolding Recursive Autoencoders for Paraphrase Detection. Advances in Neural Information Processing Systems 24 (NIPS 2011) (pp. 1-9). Granada, Spain: Neural Information Processing Systems (NIPS).

Socher, R., Lin, C. C.-Y., Ng, A. Y., \& Manning, C. D. (2011). Parsing Natural Scenes and Natural Language with Recursive Neural Networks. International Conference on Machine Learning (ICML). Bellevue, Washington, USA: International Machine Learning Society (IMLS).

Socher, R., Pennington, J., Huang, E. H., Ng, A. Y., \& Manning, C. D. (2011). Semi-Supervised Recursive Autoencoders for Predicting Sentiment Distributions. Proceedings of the 2011 Conference on Empirical Methods in Natural Language Processing (pp. 151-161). Edinburgh, Scotland, UK: Association for Computational Linguistics.

Socher, R., Perelygin, A., Wu, J. Y., Chuang, J., Manning, C. D., Ng, A. Y., \& Potts, C. (2013). Recursive Deep Models for Semantic Compositionality Over a Sentiment Treebank. . Proceedings of the 2013 Conference on Empirical Methods in Natural Language Processing (pp. 1631-1642). Seattle, Washington, USA: Association for Computational Linguistics.

Taskar, B., Klein, D., Collins, M., Koller, D., \& Manning, C. (2004). Max-Margin Parsing. Proceedings of the 2004 Conference on Empirical Methods in Natural Language Processing.

Upadhyay, S., Chang, M.-W., Chang, K.-W., \& Yih, W.-t. (2016). Learning from Explicit and Implicit Supervision Jointly For Algebra Word Problems. Proceedings of the 2016 Conference on Empirical Methods in Natural Language Processing (pp. 297-306). Austin, Texas: Association for Computational Linguistics.

Wang, L., Zhang, D., Gao, L., Song, J., Guo, L., \& Shen, H. T. (2018). MathDQN: Solving Arithmetic Word Problems via Deep Reinforcement Learning. The Thirty-Second AAAI Conference on Artificial Intelligence (AAAI-18) (pp. 5545-5552). New Orleans, Louisiana, USA: AAAI Press. 
Wang, Y., Liu, X., \& Shi, S. (2017). Deep Neural Solver for Math Word Problems. Proceedings of the 2017 Conference on Empirical Methods in Natural Language Processing (pp. 845-854). Copenhagen, Denmark: Association for Computational Linguistics.

Zhou, L., Dai, S., \& Chen, L. (2015 ). Learn to Solve Algebra Word Problems Using Quadratic Programming. Proceedings of the 2015 Conference on Empirical Methods in Natural Language Processing (pp. 817-822). Lisbon, Portugal: Association for Computational Linguistics.

Zhu, M., Zhang, Y., Chen, W., Zhang, M., \& Zhu, J. (2013). Fast and Accurate Shift-Reduce Constituent Parsing. Proceedings of the 51st Annual Meeting of the Association for Computational Linguistics (pp. 434443). Sofia, Bulgaria: Association for Computational Linguistics. 